\title{
新工科背景下《机器视觉与人工智能》课程教学改革探索 一以无锡太湖学院为例
}

\author{
Exploration on Teaching Reform of Machine Vision and Artificial Intelligence \\ in the Background of New Engineering
}

- Take Wuxi Taihu University as an Example

\section{王涛 ${ }^{1,2}$ 刘晨 $^{1}$ 张乐 $^{2}$ 方光辉 $^{1}$}

Tao Wang ${ }^{1,2}$ Chen Liu ${ }^{1}$ Le Zhang ${ }^{2}$ Guanghui Fang ${ }^{1}$

\section{1.无锡太湖学院 物联网工程学院}

中国・江苏 无锡 214000 ;

2.江苏省物联网重点建设实验室

中国・江苏 无锡 214000

1.School of Internet of Things Engineering,

Wuxi Taihu University,

Wuxi, Jiangsu, 214000, China;

2.Jiangsu Province Internet of Things Key

Construction Laboratory,

Wuxi, Jiangsu, 214000, China

基金项目: 本文系无锡市科协软科学研 究课题(KX-19-C38)、无锡太湖学院 2018

年教学改革研究课题 (JGYJ2018047)、 企业委托横向项目 (18WURD008)的研 究成果
【摘 要】《机器视觉与人工智能》是自动化专业一门多学科交叉的专业课程, 知识覆盖面 广。针对高校专业课程传统“填鸭式”教学现状, 为加快新工科体系建设, 采用成果导向教 育 $(\mathrm{OBE}$ ) 理念进行课程教学改革探索。以能力输出为导向设计新课程目标, 立足落实培养 目标进行课程教学设计, 注重教学过程多维度考核, 通过教学反馈闭环建立持续改进机 制, 以期望从目标到教学的反向设计, 从教学到评价的正向实施, 形成以学生为中心、以能 力产出为精鲔的持续改进的新课程体系。

【Abstract】"Machine Vision and Artificial Intelligence" is a multidisciplinary professional course for automation majors with a wide range of knowledge. In view of the traditional "cramming" teaching status of professional courses in colleges and universities, in order to speed up the construction of new engineering system, the concept of instruction-oriented education (OBE) is used to explore the curriculum reform. Guided by the ability output to design new curriculum objectives, based on the implementation of training objectives for curriculum design, focus on the multi-dimensional assessment of the teaching process, through the closed loop of teaching feedback to establish a continuous improvement mechanism, in anticipation of the reverse design from the goal to the teaching, from teaching to evaluation The positive implementation of the new curriculum system with student-centered, ability-output as the essence and continuous improvement.

【关键词】机器视觉; 人工智能; $O B E$ 理念; 教学设计

【Keywords \machine vision; artificial intelligence; OBE concept; instructional design 【DOI】10.36012/sde.v2i1.816

\section{1 引言}

作为人工智能范畴最重要的前沿分支之一，机器视觉在 诸多领域不断得到应用,从工业生产到社会生活处处可见。结 合无锡以及苏南地区智能制造产业布局和相关企业需求, 《机 器视觉与人工智能》课程被纳入本院自动化专业 2018 级人才 培养方案。新课程将面临着课程目标制订、教学环节设计、学
生能力培养以服务地方经济发展等迫切问题。2017 年, 教育 部高教司发布了关于开展新工科研究和实践的通知, 经过相 关讨论形成了北京指南、复旦共识等新工科指导意见 ${ }^{[1}$ 。随着 专业工程教育认证的推行, 推进《机器视觉与人工智能》课程 教学改革, 遵循以学生为中心、以能力输出为导向的持续改进 的教学理念, 突出学生知识、素养、能力三维度的教学目标是 当前实际教学活动亟需解决的问题。围绕上述问题, 在新工科 
背景下, 本课题以 OBE 教学理念为指导, 确定《机器视觉与人 工智能》课程教学改革思路, 以学生能力输出为导向, 重新制 订课程目标、教学体系和评价机制,提升整体教学质量。

\section{OBE 理念驱动的《机器视觉与人工智 能》课程教学改革思路}

OBE 教学设计者在进行教学设计前需要明确 4 大核心问 题: 希望学生取得什么成果? 为什么让学生取得这些成果? 怎 么有效帮助学生取得这些成果? 如何知道学生已取得这些成 果? 这里的成果是学生通过一段学习后所能达到的最大能力。

《机器视觉与人工智能》作为自动化专业 2018 人才培养 方案新加入课程, 传统课程教学理念不再适用新工科背景的 教学活动。首先, 传统教学目标是以教学内容掌握情况为依 据, 教师是教学中心, 强调知识传授, 导致学生无法学以致用; 其次,学生成果评价过分依赖期末考核,忽略了对学生能力的 过程评价; 最后, 教学质量监控缺少“闭环”,没有建立有效的 持续改进机制。针对上述挑战, 本课题以 OBE 理念为核心, 确 定从课程目标、教学设计、评价机制 3 个方面对《机器视觉与 人工智能》课程进行改革, 覆盖了 $\mathrm{OBE}$ 理念提出的 4 大核心 问题。

\section{3 反向设计,正向实施原则下的新的课程}

\section{目标}

OBE 实施首先要确定学习成果。最终的学习成果既是终 点, 也是其起点。新的课程目标设置应遵循反向设计原则, 聚焦 学生的自我需求和社会需求, 由需求决定培养目标, 从而确定 课程培养目标, 再由课程目标正向实施设计课程教学, 充分调 动学生内驱力, 强调成果导向。引入教学评价成为教学过程一 部分, 通过全过程考核, 实现对学生过程的管理、引导和评价。

根据自动化专业历届毕业生就业情况调查分析, 超过
$80 \%$ 的用人单位从学生个人品质和专业能力双方面考查毕业 生。因此,专业人才培养需覆盖学生的个人素质和专业素质两 方面。参照无锡太湖学院自动化专业人才培养目标, 本文将 《机器视觉和人工智》课程目标细化为知识目标、素养目标和 能力目标 3 个维度, 实施过程中根据学生个人、社会和专业需 求, 结合教学评价反馈动态调整。7 个新课程目标将与教学内 容、教学环节和教学评价直接关联, 为课程的目标达成度评估 提供依据,进而构建持续改进的闭环机制。

\section{4 以学生为中心的课程教学设计}

课程教学设计要根据课程目标有针对性的展开, OBE 核 心理念依旧离不开因材施教, 围绕学生要获得怎样的能力和 素养开展教学, 设计多样的教学方法, 通过培养学生兴趣, 达 到提高学习效率的目的 ${ }^{[2]}$ 。

《机器视觉与人工智能》课程选用西安电子科技大学出版 社, 刘国华主编的《HALCON 数字图像处理》作为教材。根据 教材结构, 将本课程内容分为 4 个教学模块, 每个教学模块与 课程目标都有清晰的映射关系, 保障学生每一项能力输出都 有明确的支撑模块。在课程目标指引下, 确定每个模块的教学 方法和学习成果形式, 表 1 展示了每个模块的教学设计内容。

\section{1 “灌输式”向“对话式”转变的翻转课堂引入}

翻转课堂是一种以信息技术为手段、以学习者为中心, 将 数字化融入教学过程的教学模式, 是对传统课堂教学的逆序 创新 ${ }^{[3]}$ 。《机器视觉与人工智能》课程内容覆盖面较广, 从机器 视觉系统到数字图像处理, 再到人工智能, 多学科交叉, 清晰 地认识这些内容关系十分重要。为了方便学生对课程的理解, 不仅需要老师课堂的引领, 还要求学生根据老师课上提出的 问题进行课后调研、查找资料或观看视频讲座等, 以课堂上讨 论的方式进行学习, 将传统单向灌输的知识对话课堂转变成

表 1 基于 $O B E$ 理念的《机器视觉与人工智能》课程教学设计一览表

\begin{tabular}{|c|c|c|c|}
\hline 模块 & 内容 & 教学方法 & 学习成果 \\
\hline $\begin{array}{l}\text { 第一模块 } \\
\text { 基础概念 }\end{array}$ & $\begin{array}{l}\text { 机器视觉基本概念、系统组成及发 } \\
\text { 展趋势; } \\
\text { HALCON 概述; } \\
\text { 数字图像处理概论 }\end{array}$ & $\begin{array}{l}\text { 教师讲授、 } \\
\text { 小组讨论、 } \\
\text { 观看视频、 } \\
\text { 翻转课堂 }\end{array}$ & $\begin{array}{c}\text { 综述调研作业材料、 } \\
\text { 课堂讨论 }\end{array}$ \\
\hline $\begin{array}{c}\text { 第二模块 } \\
\text { 数字图像处理 }\end{array}$ & $\begin{array}{l}\text { 图像数字化; } \\
\text { 数字图像运算、增强、分割、匹配; } \\
\text { 图像形态学 }\end{array}$ & $\begin{array}{l}\text { 教师讲授、 } \\
\text { 案例教学、 } \\
\text { 小组讨论、 } \\
\text { 观看视频 }\end{array}$ & $\begin{array}{l}\text { 作业材料、 } \\
\text { 课堂讨论、 } \\
\text { 案例分析报告 }\end{array}$ \\
\hline $\begin{array}{c}\text { 第三模块 } \\
\text { HALCON 图像处理工具 }\end{array}$ & $\begin{array}{l}\text { HALCON 图像处理基础编程; } \\
\text { HALCON 数据结构 }\end{array}$ & $\begin{array}{l}\text { 教师讲授、 } \\
\text { 案例教学、 } \\
\text { 小组讨论 }\end{array}$ & $\begin{array}{c}\text { HALCON 程序设计报告、 } \\
\text { 作业材料、 } \\
\text { 课堂讨论 }\end{array}$ \\
\hline $\begin{array}{c}\text { 第四模块 } \\
\text { HALCON 相关实例和算法 }\end{array}$ & $\begin{array}{l}\text { 字符分割识别; } \\
\text { 条形码识别; } \\
\text { 去雾算法 }\end{array}$ & $\begin{array}{l}\text { 翻转课堂、 } \\
\text { 项目教学、 } \\
\text { 小组讨论 }\end{array}$ & 项目综合报告 \\
\hline
\end{tabular}


多向交流,充分发挥学生的主体角色。学生通过自主学习将所 学理论知识贯通起来, 开放式的教学模式使得学生了解到课 内学时无法覆盖的信息,丰富了学生的知识面, 更培养了学生 自主学习能力与沟通交流能力。

\section{2 “知识课堂”向 “能力课堂”转变的项目教学}

\section{引入}

在《机器视觉与人工智能》课程教学中, HALCON 相关实
不清晰, 过分依赖期末评测成绩, 无法多方位衡量学生能力输 出成果, 也无法衡量课程目标达成度。教学组一改传统“平时成 绩+期末考核”评价方式,采用匹配课程目标的多维度考核,加 大过程考核比重, 确定如表 2 所示的课程目标达成度综合表。

\section{6 结语}

本文将 OBE 理念应用到《机器视觉与人工智能》课程教

表 2 《机器视觉与人工智能》课程目标达成度综合表

\begin{tabular}{|c|c|c|c|}
\hline 评价依据 & 评价指标 & 所占比重 $(\%)$ & 评价人员 \\
\hline 综述调研作业材料;案例分析报告 & $\begin{array}{l}\text { 综述准确精简、覆盖面广而有条理; 案例报告分析条理清 } \\
\text { 晰准确 }\end{array}$ & 10 & 教师 \\
\hline 课堂讨论;项目综合报告 & $\begin{array}{l}\text { 才才分工明确, 合作意识好, 且观点表达明确; 项目报告 } \\
\text { 中工作内容充分且内容条理清晰 }\end{array}$ & 10 & 项目组 \\
\hline 综述调研作业材料;课堂讨论 & 综述中针对机器视觉内容调研充分, 条理清晰 & 10 & 教师 \\
\hline 作业材料;课堂讨论;案例分析报告 & 作业完成质量高; 案例分析报告条理清晰且结果可复现 & 20 & 项目组 \\
\hline 综述调研作业材料 & $\begin{array}{l}\text { 综述中针对人工智能以及与机器视觉的关系调研充分, } \\
\text { 条理清晰 }\end{array}$ & 10 & 教师 \\
\hline HALCON 程序设计报告;作业材料 & $\begin{array}{l}\text { 作业完成质量高; HALCON 程序设计报告条理清晰且结 } \\
\text { 果可复现 }\end{array}$ & 10 & 教师 \\
\hline 项目综合报告 & 项目报告完备, 文字精简有条理, 且方案可实施 & 20 & 项目组 \\
\hline 期末考核 & 期末试卷考试情况 & 10 & 教师 \\
\hline
\end{tabular}

例和算法是很重要的一部分内容。传统的教学方法是以课堂 讲解、分析为主, 老师满堂灌, 学生被动听, 无法保证学生能力 培养目标。为了培养学生解决工程问题能力, 本课程引入工程 实际问题,如字符分割识别、条形码识别等,作为项目研究课 题, 以“基于项目的教学”为手段,建立在真实世界的产品和系 统的“构思-设计-实现-运行”过程上的工程教育思想。教学 班级以小组为单位, 至少 5 人一组, 针对项目需求, 小组成员 自行分工, 推选团队负责人, 以工程思想为指导, 进行项目需 求调研、总体方案设计、可行性分析、方案软、硬件选型和设计 开发、运行验证,最终形成完整的项目综合报告。项目研究实 施过程中，需要学生能够查阅文献分析工程的关键环节和参 数, 综合应用机器视觉、图像分析、人工智能等知识, 结合相关 工程软件进行仿真验证, 提出优化方案。通过项目教学, 学生 解决复杂工程问题能力便可以得到提升。

\section{5 构建多维度评价机制,形成持续改进闭环}

传统的教学评价方式过于单一,考核内容与课程目标关联
学改革中, 结合新工科背景下能力输出为导向的人才培养需 求, 从知识、能力、素养三维度对课程教学目标、教学设计、评 价体系进行了改革, 通过多渠道反馈方式, 构建教学闭环系统 形成持续改进机制, 使得课程教学能够与时俱进, 适应本校自 动化专业人才培养要求。在未来教学过程中, 笔者将以此教学 设计指导教学实践,并加以完善,进一步提升教学效果。

\section{参考文献}

[1]王晶心,原帅,赵国栋、混合式教学对大学生学习成效的影响一 基于国内一流大学 $\mathrm{MOOC}$ 应用效果的实证研究 [J].现代远距离教育, 2018(5):39-47.

[2]张志美,程立英,李柳,等.基于 OBE 教学理念的《信号与系统》 课程改革[J].沈阳师范大学学报(自然科学版),2019,37(3):284-288.

[3] 陈维维.MOOC、SPOC、微课、翻转课堂:概念辨析与应用反思 [J].南京晓庄学院学报,2015(6):117. 